\title{
Pengaruh Financial Attitude, Financial Education, Financial Knowledge, Financial Experience, dan Financial Behavior terhadap Financial Literacy pada Pelajar Kota Batam
}

\author{
Fity Justyn ${ }^{1)}$, Dewi Khornida Marheni' ${ }^{2)}$ \\ ${ }^{1}$ Fakultas Ekonomi, Universitas Internasional Batam, Jl. Gajah Mada, Sei Ladi, Tiban \\ email: fityjustynftn@gmail.com \\ ${ }^{2}$ Fakultas Ekonomi, Universitas Internasional Batam, Jl. Gajah Mada, Sei Ladi, Tiban \\ email: dewi@uib.ac.id
}

\begin{abstract}
This study aims to analyze the relationship of several variables, namely Financial Attitude, Financial Education, Financial Knowledge, Financial Experience, and Financial Behavior to Financial Literacy in Students in Batam City. In this study using a quantitative approach, as well as primary data which is the source of data collected through the distribution of questionnaires as many as 450 respondents in the form of students in Batam City. Some questionnaires could not be processed because they were not filled out completely after the data collected were processed through a software application called SPSS version 23. The results of the study stated that financial attitude and financial experience had a significant positive effect on financial literacy, financial behavior had a significant negative effect on financial literacy, while financial knowledge and financial education do not have a significant effect on financial literacy.
\end{abstract}

Keywords: financial attitudes, financial education, financial knowledge, financial experience, financial behavior, financial literacy.

\begin{abstract}
Abstrak
Penelitian ini memiliki tujuan dalam menganalisa hubungan dari beberapa variabel yaitu Financial Attitude, Financial Education, Financial Knowledge, Financial Experience, dan Financial Behavior terhadap Financial Literacy pada Pelajar yang ada di Kota Batam. Pada penelitian ini menggunakan pendekatan kuantitatif, serta data primer yang menjadi sumber data yang dikumpulkan melalui penyebaran kuesioner sebanyak 450 responden yang berupa pelajar di Kota Batam. Beberapa kuesioner tidak dapat diolah karena tidak diisi dengan lengkap, setelah terkumpul data tersebut diolah melalui aplikasi perangkat lunak dengan nama SPSS versi 23. Hasil penelitian menyatakan bahwa financial attitude dan financial experience berpengaruh signifikan positif terhadap financial literacy, financial behavior berpengaruh signifikan negatif terhadap financial literacy, sedangkan financial knowledge dan financial education tidak mempunyai pengaruh signifikan terhadap financial literacy.
\end{abstract}

Kata Kunci : sikap keuangan, pendidikan keuangan, pengetahuan keuangan, pengalaman keuangan, perilaku keuangan, literasi keuangan. 


\section{PENDAHULUAN}

Pada dasarnya masyarakat tidak lepas dari keberadaan globalisasi, baik mengenai investasi, trade atau dagangan, serta budaya yang popular. Dulu, keberadaan mall dan minimarket sangat terbatas. Oleh karena itu, masyarakat menjadi susah untuk meraih barang yang menjadi pemenuh kebutuhan hidup masyarakat. Pada jaman sekarang, sebagian besar tempat telah terletak mall,

minimarket, online shop yang membuat masyarakat lebih mengutamakan keinginan dibandingkan kebutuhan, seperti membeli barang yang seharusnya tidak diperlukan agar tidak tertinggal jaman, masyarakat juga tidak menyadari telah memfoya-foyakan uangnya. Apalagi online shop yang beredar pada kalangan tersebut memiliki sistem pembayaran yang murah sehingga masyarakat dapat mencari yang diinginkan kapanpun dan dimanapun (Adiana, 2015).

Financial Literacy merupakan hal yang diperhatikan di berbagai negara karena setiap negara menginginkan penduduknya memiliki pemikiran yang luas sehingga menghasilkan masa depan yang cemerlang. Maka itu, proses literasi keuangan harus membawa hasil positif di negara tersebut. Masyarakat tidak akan mendalami konsep keuangan dan tidak akan memiliki pengetahuan untuk memutuskan keuangan masa depannya. Menurut (Widiyati et al., 2018), literasi keuangan dipahami sebagai kombinasi dari kesadaran keuangan, pengetahuan keuangan, keterampilan, sikap dan perilaku yang diperlukan dalam merancang keputusan keuangan secara tepat dan akan memberikan kesejahteraan individu.

Financial Attitude merupakan sikap penting dalam mencapai keberhasilan atau kegagalan aspek keuangan. Sikap yang baik akan mempengaruhi perilaku yang baik. Perilaku manajemen keuangan yang baik dan tepat dapat dimulai dengan menerapkan sikap finansial yang baik dan tepat. Tanpa penerapan sikap yang baik, akan sulit bagi mahasiswa untuk memiliki tabungan dalam jangka panjang (Ameliawati \& Setiyani, 2018). Sikap keuangan bertujuan untuk memilih tujuan keuangannya serta melakukan perencanaan akan keuangan.

Financial Education bukan hanya tentang uang saku, tabungan, pendapatan maupun pengeluaran, dimana Financial Education merupakan suatu pemahaman masyarakat tentang cara uang bekerja di dunia nyata. Menurut penelitian (KoranSINDO, 2019) menyatakan bahwa tingkat literasi keuangan di Indonesia rendah, dimana pendidikan akan keuangan harus diketahui dari awal. Khamim menjelaskan bahwa literasi keuangan sangat penting dijelaskan sejak awal kepada siswa agar dapat menciptakan perilaku seseorang dalam menggunakan uang yang diterimanya secara efisien. Ketika pendidikan keuangan masyarakat membaik akan membawa masyarakat untuk memikierkan lebih matang dalam mengelola keuangannya seperti apa yang lebih diprioritaskan, dan tidak memboros uang sembarangan.

Melalui Otoritas Jasa Keuangan, (Jatmiko, 2018) menjelaskan bahwa perencanaan keuangan menjadi salah satu jalan untuk merencanakan masa depan yang baik. Rendahnya tingkat pengetahuan (Financial Knowledge) akan literasi keuangan dalam pengelolaan keuangan yang baik akan memberi hambatan akses ke lembaga keuangan dan mempermudah masyarakat untuk dipengaruhi oleh hal-hal berkaitan dengan keuangan yang tidak resmi dengan kata lain akan menghambat jalannya pembangunan ekonomi suatu negara.

Kebanyakan orang memutuskan sesuatu berdasarkan apa yang telah terjadi. Dalam hal keuangan, pengalaman menjadi faktor yang tidak kalah pentingnya bagi seseorang dalam kaitannya dengan perilaku manajemen keuangan. Semakin banyak Financial Experience seseorang, semakin baik perilaku dalam mengelola keuangan, karena seseorang yang memiliki banyak pengalaman di bidang keuangan mampu 
membedakan apakah yang wajib dilakukan serta tidak wajib dilakukan, selain itu telah memahami resiko apa yang akan terjadi, dimana akan terjadi jika seseorang yang akan mengelola keuangan dengan pengalaman keuangan rendah maka perilaku pengelolaannya tidak akan baik (Ameliawati \& Setiyani, 2018).

Financial Behavior adalah hal yang tidak dapat dihindarkan pada jaman sekarang, khususnya yang memiliki kaitan dengan perilaku konsumsi masyarakat. Sebagian besar masyarakat memiliki pemikiran jangka pendek, kurang tanggung jawab pada pengambilan keputusan keuangan, dimana akan mendatangkan masalah-masalah keuangan jika tidak mengikuti perencanaan keuangan yang tepat (Kholilah \& Iramani, 2013). Sebenarnya, pengetahuan keuangan dan sikap membentuk perilaku seseorang melalui praktek budgeting, pembayaran tepat waktu, menabung uang, mengatur hutang kartu kredit, dan adanya ide untuk kekayaan bersih mereka sendiri.

Menurut (Segara, 2016) pada tahun 2016, hasil penelitian OJK atau Otoritas Jasa Keuangan menjelaskan tentang literasi keuangan berdasarkan strata wilayah di Indonesia.

\begin{tabular}{|l|l|l|l|}
\hline $\begin{array}{l}\text { No } \\
\cdot\end{array}$ & $\begin{array}{l}\text { Nama } \\
\text { Provinsi }\end{array}$ & $\begin{array}{l}\text { Nama } \\
\text { Kota/Kabu } \\
\text { paten }\end{array}$ & $\begin{array}{l}\text { Indeks } \\
\text { Literasi } \\
\text { Keuangan }\end{array}$ \\
\hline 1. & $\begin{array}{l}\text { DKI } \\
\text { Jakarta }\end{array}$ & $\begin{array}{l}\text { Jakarta } \\
\text { Selatan }\end{array}$ & $58,4 \%$ \\
\hline 2. & $\begin{array}{l}\text { Jawa } \\
\text { Barat }\end{array}$ & Bandung & $49,2 \%$ \\
\hline 3. & $\begin{array}{l}\text { Jawa } \\
\text { Timur }\end{array}$ & Surabaya & $45,9 \%$ \\
\hline 4. & $\begin{array}{l}\text { DI } \\
\text { Yogyakar } \\
\text { ta }\end{array}$ & Yogyakata & $44,5 \%$ \\
\hline 5. & $\begin{array}{l}\text { Jawa } \\
\text { Tengah }\end{array}$ & Semarang & $44,1 \%$ \\
\hline 6. & Riau & Pekanbaru & $43,1 \%$ \\
\hline 7. & Bali & Denpasar & $42,9 \%$ \\
\hline 8. & Banten & Tangerang & $40,9 \%$ \\
\hline 9. & $\begin{array}{l}\text { Kalimant } \\
\text { an Timur }\end{array}$ & Samarinda & $40,9 \%$ \\
\hline
\end{tabular}

\begin{tabular}{|c|l|l|l|}
\hline 10. & Aceh & $\begin{array}{l}\text { Banda } \\
\text { Aceh }\end{array}$ & $40,4 \%$ \\
\hline 11. & $\begin{array}{l}\text { Kalimant } \\
\text { an Barat }\end{array}$ & Pontianak & $40,1 \%$ \\
\hline 12. & $\begin{array}{l}\text { Sulawesi } \\
\text { Selatan }\end{array}$ & Makassar & $37,2 \%$ \\
\hline 13. & $\begin{array}{l}\text { Kepulaua } \\
\text { n Riau }\end{array}$ & Batam & $37,1 \%$ \\
\hline
\end{tabular}

Dari tabel diatas diketahui bahwa Batam memiliki indeks literasi keuangan sebesar $37,1 \%$ sedangkan indeks literasi keuangan tertinggi terdapat pada wilayah Jakarta Selatan sebesar 58,4\% dan yang terendah terdapat pada wilayah Indragiri Hilir pada Provinsi Riau sebesar 15,9\%. Hasil tersebut menyatakan Batam memiliki literasi keuangan yang rendah dimana dibutuhkan peningkatan literasi masyarakat melalui peningkatan pengetahuan masyarakat akan cara mengelola keuangan yang baik dan benar, keterampilan tentang bagaimana cara menghitung bunga, denda, serta hasil investasi apakah yang menguntungkan sehingga masyarakat dapat mengetahui kegunaan, dan resiko dari produk maupun jasa keuangan.

\section{KERANGKA TEORITIS DAN PERUMUSAN HIPOTESIS}

Literasi keuangan secara umum dapat dijelaskan sebagai suatu kemampuan seseorang dalam mengerti, menganalisa, mengelola, serta mengatasi permasalahan keuangan secara pribadi (Sohn, Joo, Grable, Lee, \& Kim, 2012). Literasi keuangan sebagai kemampuan menilai melalui pengambilan keputusan yang efektif terkait pemakaian, dan pengelolaan uang. Literasi keuangan baik jika memahami konsep mengelola keuangan, pengetahuan akan lembaga keuangan serta sikap memungkinkan pengelolaan keuangan yang efektif serta tanggung jawab (Albeerdy \& Gharleghi, 2015).

Literasi keuangan merupakan kemampuan masyarakat membuat ataupun mengambil keputusan keuangan demi kepentingan mereka sendiri baik dari jangka pendek maupun jangka panjang, 
dimana mengharuskan masyarakat untuk memiliki pemahaman yang baik tentang konsep keuangan seperti inflasi, bunga majemuk dan resiko yang beragam. Pemerintah mengalihkan tanggung jawab atas tabungan pensiun kepada individu oleh karena itu, individu perlu memahami hubungan antara resiko dan pengembalian, cara menilai resiko, konsep diversifikasi resiko dan cara memantau kinerja investasi mereka dengan mempertimbangkan biaya yang dikeluarkan (Bart Frinjs et al., 2014).

Bart Frinjs et al., 2014 juga menjelaskan financial literacy yang buruk cenderung membuat kesalahan keuangan, lebih sedikit menabung, gagal dalam membuat rencana pensiun, meremehkan efek bunga majemuk, serta mengandalkan hutang seperti kartu kredit, dengan adanya literasi yang buruk akan terjadinya kemungkinan untuk bangkrut, lebih sedikitnya kekayaan, dan rentan krisis keuangan. Sedangkan financial literacy yang baik mempunyai peluang lebih besar untuk melakukan investasi pada reksa dana yang berbiaya rendah, berpastisipasi dalam pasar saham yang lebih besar, serta membantu mengurangi masalah keuangan, mendorong mereka tanggung jawab pada keuangan dan membantu meningkatkan efisiensi pada organisasi.

Hubungan financial attitude terhadap financial literacy menurut penelitian yang dilakukan oleh Widiyati et al., (2018) menyatakan bahwa kebiasaan baik dalam pengelolaan uang membawa hasil literasi yang lebih baik. ketika sikap keuangan meningkat, pengelolaan keuangan masyarakat menjadi benar. Sehingga jika persepsi seseorang tentang keuangan negative, masyarakat tidak akan berupaya mempelajari cara mengelola keuangan dengan benar. Masyarakat yang memiliki sikap dan pola pikir benar terhadap uang akan lebih rentan dalam perencanaan keuangan awal dan tabungan, dimana akan menghalangi peluang masyarakat untuk bangkrut atau gagal menikmati penghematan uang. Masyarakat tidak meningkatkan kemampuan berpikir dalam meningkatkan pengetahuan mengenai topik yang masyarakat sukai dalam mengelola keuangannya sendiri. Hal tersebut terdapat dukungan penelitian yang dilakukan oleh Ameliawati \& Setiyani, (2018), Sohn et al., (2012), Albeerdy \& Gharleghi, (2015), Kadoya \& Khan, (2017), Rai et al., (2019), Te'eni-Harari, (2016), Venkataraman \& Venkatesan, (2018), Kane et al., (2016), dan Rahman et al., (2018). Adapun hasil penelitian dimana diteliti oleh Isomidinova \& Singh, (2017) menjelaskan dimana financial attitude berhubungan tidak signifikan terhadap financial literacy. Karena tingkat kepercayaan rendah, sikap tidak peduli yang mengacu pemborosan. Masyarakat tidak berinisiatif untuk meningkatkan pengetahuan, sikap dan perilaku keuangan, serta perbedaan jenis kelamin, usia, dan domisili menyebabkan sikap keuangan setiap masyarakat berbeda-beda. Hal ini didukung oleh Agarwalla et al., (2015), Setyawati \& Suroso, (2017), Candiya Bongomin et al., (2017), dan Choudhary et al., (2017).

Hubungan financial education terhadap financial literacy menurut penelitian yang dilakukan oleh Chung \& Park, (2016) menyatakan bahwa dengan adanya pendidikan masyarakat dapat meningkatkan pengetahuan akan uang sehingga masyarakat paham cara mengelola keuangan. Semakin tinggi tingkat pendidikan seseorang, memudahkan individu untuk memahami informasi serta menerapkannya pada perilaku serta gaya hidup sehari-hari. Adanya pendidikan keuangan membantu kaum muda meminimalkan biaya yang timbul dalam mengelola hutang mereka dan meningkatkan kemampuan keuangan masyarakat. Orang tua berperan penting dalam pendidikan keuangan seorang anak. Sehingga ketika terjadi goncangan pendapatan atau keadaan darurat, maka orang tua menjadi salah satu yang bertanggung jawab untuk mempengaruhi pengetahuan anak-anak dari sekarang. Karena hal tersebut akan membantu 
meningkatkan tabungan masyarakat, pendapatan, dan meningkatkan kesejahteraan. Pendidikan keuangan yang baik membantu masyarakat dalam mengambil keputusan, memperbaiki kesalahan keuangan. Sebagian besar mahasiswa hanya memiliki pemahaman yang cukup, informasi yang diperoleh mahasiswa selama proses pembelajaran tidak cukup baik. Sehingga semua materi yang disampaikan oleh dosen masih relatif secara teoritis belum diimplementasi. Hasil ini didukung oleh Albeerdy \& Gharleghi,( 2015), Isomidinova \& Singh, (2017), Dewanty \& Isbanah, (2018), de Bassa Scheresberg, (2013), Potrich et al., (2015), Suparti, (2016), Lusardi, (2012), Y1ldırım et al., (2017), Kebede \& Kuar, (2015), Alex \& Amos, (2014), Nidar \& Bestari, (2012), Murugiah, (2016), dan Fernandes et al., (2014). Sedangkan penelitian yang dilakukan oleh Thomas, Mulyono, Setiaji, \& Thomas, (2016) menjelaskan bahwa financial education tidak signifikan terhadap financial literacy karena mahasiswa Semarang menyatakan bahwa baik pendidikan keuangan tinggi maupun rendah, tidak terdapat hubungan dengan cara mengelola keuangannya.

Hubungan financial knowledge terhadap financial literacy menurut penelitian Widiyati et al., (2018) menjelaskan bahwa masyarakat memahami fungsi tabungan, memahami cara menghitung bunga sehingga meningkatkan literasi masyarakat terhadap keuangan. Semakin baik cara menabung seseorang, semakin tinggi minat untuk memiliki perencanaan pensiun, dimana masyarakat akan berpikir secara jangka panjang untuk masa depannya. Pengetahuan membantu seseorang menghindari terjadinya penipuan uang, mengajarka pendekatan yang baik dan benar dalam berinvestasi untuk kebutuhan masa depan dan membeli jenis asuransi yang tepat. Pengetahuan keuangan diperlukan karena dengan adanya pengetahuan pada uang, masyarakat lebih kompeten dalam menghadapi masalah keuangan. Masyarakat tidak dapat berhitung dengan benar karena memiliki pengetahuan keuangan yang rendah dan kurang kesadaran pentingnya uang. Sebagian besar mahasiswa tidak mengetahui cara mengelola penghasilan mereka akibat kurangnya literasi keuangan, sehingga mahasiswa melakukan pengeluaran berdasarkan keinginan, tidak berdasarkan kebutuhan. Hasil tersebut didukung oleh de Bassa Scheresberg, (2013), Mwange, Lis, Epm, Ib, \& Candidate, (2017), Venkataraman \& Venkatesan, (2018), Kane et al., (2016), Rahman et al., (2018), Philippas \& Tzora, (2017), Thomas et al., (2016), Agarwalla et al., (2015), Setyawati \& Suroso, (2017), Candiya Bongomin et al., (2017), dan Choudhary et al., (2017). Hasil penelitian yang dilakukan Frijns, Gilbert, \& TouraniRad, (2014) menjelaskan bahwa financial knowledge tidak signifikan terhadap financial literacy karena tidak terdapat pengetahuan keuangan yang mempengaruhi literasi keuangan, sehingga pelajar tidak dapat mengelola keuangannya. Selain itu, pengetahuan mahasiswa UiTM sama sekali tidak memiliki hubungan dengan literasi keuangan mahasiswa sehingga cara mengatur keuangan mahasiswa. Hasil tersebut juga didukung oleh Rai et al., (2019), dan Ibrahim et al., (2009).

Hubungan antara financial experience terhadap financial literacy menurut Ameliawati \& Setiyani, (2018) menyatakan bahwa literasi keuangan kurang lengkap jika tidak adanya pengalaman keuangan. orang yang memiliki banyak pengalaman keuangan, mereka akan memiliki tingkat literasi yang baik, sebaliknya jika seseorang tidak memiliki pengalaman yang cukup maka tingkat literasi keuangan yang dimiliki rendah. Hasil penelitian tersebut didukung oleh Sohn et al., (2012), Frijns et al., (2014), Bartley, (2011), Floyd, (2015), dan Fazli Sabri et al., (2010). Sedangkan hasil penelitian yang dilakukan Kadoya \& Khan, (2017) menyatakan financial 
experience tidak signifikan terhadap financial literacy karena Jepang tidak menyetujui bahwa pencapaian literasi keuangan melalui pengalaman mulai berkurang pada usia lanjut. Adapun hasil penelitian yang dilakukan Suparti, (2016) menjelaskan bahwa financial experience tidak signifikan terhadap financial literacy karena lamanya pengalaman kerja tidak menjamin seseorang akan lebih bijak dalam menggunakan uangnya.

Hubungan financial behavior terhadap financial literacy menurut Widiyati et al., (2018) menjelaskan bahwa masyarakat memiliki persepsi, kemampuan dalam membaca, menganalisa keuangan, mengelola serta memahami kondisi keuangan bisnis mereka. Selain itu, mahasiswa mempunyai perilaku keuangan yang baik dapat mengatur tabungan dimana akan diperlukan untuk pensiun, tabungan atau penyimpanan untuk dana darurat, investasi, kredit dan asuransi. Perilaku keuangan yang baik diukur melalui cara mengatur uangnya secara baik, cara menabung seperti pendapatannya dan penggunaannya, serta perilaku investasinya. Hasil penelitian ini didukung oleh Nicolini \& Nicolini, (2019), Graf, (2012), Beckmann, (2013), Rai et al., (2019), Mudzingiri et al., (2018), Kane et al., (2016), Rahman et al., (2018), dan Fernandes et al., (2014). Hasil penelitian yang dilakukan Yong et al., (2018)menyatakan bahwa financial behavior tidak signifikan terhadap financial literacy. Karena banyak anak muda yang hidup di luar kemampuan mereka dan mereka tidak memiliki perencanaan keuangan yang tepat dan oleh karena itu, upaya yang terorganisir dengan baik sangat diperlukan untuk mengubah sikap mereka. Pendapatan meningkat maka perilaku keuangan akan semakin tidak baik, adanya inflasi yang mempengaruhi daya beli, adanya perilaku tertentu yang menghambar penggunaan dan kepercayaan pada produk keuangan formal sehingga menciptakan hambatan, serta rentan terjadinya resiko yang lebih tinggi dari pengambilan keputusan keuangan yang tidak bertanggung jawab. Hasil penelitian ini didukung oleh Agarwalla et al., (2015), Setyawati \& Suroso, (2017), dan Choudhary et al., (2017). Hasil penelitian yang dilaksanakan Venkataraman \& Venkatesan, (2018), mengatakan bahwa financial behavior memiliki hubungan signifikan negatif terhadapfinancial literacy karena perilaku keuangan masyarakat baik tetapi akibat rendahnya kepercayaan diri dalam mengelola keuangan individu, literasi keuangannya mahasiswa menjadi rendah. Hasil tersebut juga didukung oleh Candiya Bongomin et al., (2017).

\section{Model Penelitian}

Beberapa variabel independen yang digunakan pada penelitian adalah financial attitude, financial education, financial knowledge, financial experience, dan financial behavior.

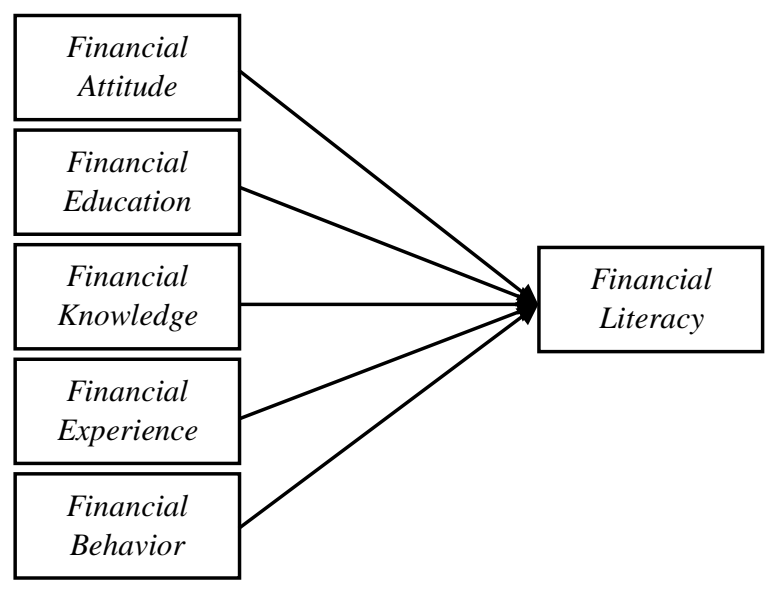

Gambar 1 Model penelitian faktor-faktor mempengaruhi Financial Literacy

Sumber: Penulis, 2019.

\section{Perumusan Hipotesis}

Hipotesis diajukan untuk mencapai tujuan penelitian adalah:

H1: Terdapat hubungan signifikan positif pada financial attitude terhadap financial literacy.

$\mathrm{H} 2$ : Terdapat hubungan signifikan positif pada financial education terhadap financial literacy.

H3: Terdapat hubungan signifikan positif pada financial knowledge terhadap financial literacy. 
H4: Terdapat hubungan signifikan positif pada financial experience terhadap financial literacy.

H5: Terdapat hubungan signifikan positif pada financia behavior terhadap financial literacy.

\section{METODE PENELITIAN}

Metode purposive sampling digunakan peneliti untuk mengumpulkan sampel dimana sampel yang didapatkan wajib sesuai dengan karakteristik yang diigninkan. Ciri-ciri tersebut diperlukan sehingga peneliti memperoleh informasi sesuai dengan tujuan. Syarat-syarat yang wajib ada dalam pengumpulan sampel seperti:

1. Pelajar atau Mahasiswa di Kota Batam (Universitas Internasional Batam, Universitas Putera Batam, Universitas Riau Kepulauan, dan Universitas Batam)

2. Telah bekerja

\section{ANALISIS DAN PEMBAHASAN}

\section{Statistik Deskriptif}

Dari 450 responden pelajar Kota Batam yang telah mengisi kuesioner, terdapat 33 kuesioner yang tidak dapat diolah, dan 417 data yang dapat diolah. Hampir seluruh responden berada dibawah umur 25 tahun karena responden merupakan mahasiswa atau pelajar. Mayoritas jenis kelamin berada pada pria sebesar $75.1 \%$ atau 313 responden. Mayoritas pelajar memiliki pendidikan terakhir SMA yaitu sebesar $67.1 \%$ atau 280 responden. Sebagian pelajar tidak bekerja sebesar $50.6 \%$ atau 221 responden, sedangkan yang berstatus mahasiswa part time terdapat $49.4 \%$ atau 206 mahasiswa. Penghasilan perbulan responden bermayoritas pada Rp.3-5juta karena rata-rata mahasiswa berpendapatan sesuai Upah Minimum Kota.

\section{Kualitatif Data}

Hasil uji validitas, terdapat variabel yang wajib dihapus akibat tidak memenuhi karakteristik dimana memiliki factor loading yang lebih kecil dari 0.5.
Sebanyak 23 pertanyaan digunakan sedangkan 10 pertanyaan dihapus.

Hasil uji reliabel cronbach's alpha yang telah diteliti secara keseluruhan, dinyatakan reliabel karena menunjukkan nilai cronbach's alpha yang melewati nilai 0.6 .

Tabel 1.Hasil Uji Kolmogorov-Smirnov

\begin{tabular}{lc}
\hline \multicolumn{2}{c}{ One-Sample Kolmogorov-Smirnov Test } \\
\hline & Undstandardized Residual \\
\hline Kolmogorov-Smirnov Z & 0,043 \\
Asvmp. Sig. (2-tailed) & 0,058 \\
\hline
\end{tabular}

Sumber: Data primer yang diolah (2019)

Tabel 1 menyatakan hasil uji normalitas dengan menggunakan Kolmogorov smirnov dengan nilai sebesar 0.058 . Rangkumannya adalah jika nilai melewati 0.05 maka variabel dikatakan tersebar normal.

Tabel 2 Hasil Uji Multikolinieritas

\begin{tabular}{|c|c|c|c|}
\hline \multicolumn{4}{|c|}{ Collinearity } \\
\hline \multirow[t]{2}{*}{ Model } & \multicolumn{2}{|c|}{ Statistic } & \multirow[t]{2}{*}{ Kesimpulan } \\
\hline & Tolerance & $V I F$ & \\
\hline Financial Attitude & 0,841 & 1,188 & Tidak terjadi multikolinearitas \\
\hline Financial Knowledge & 0,518 & 1,929 & Tidak terjadi multikolinearitas \\
\hline Financial Behavior & 0,456 & 2,194 & Tidak terjadi multikolinearitas \\
\hline Financial Education & 0,594 & 1,682 & Tidak terjadi multikolinearitas \\
\hline Financial Experience & 0,994 & 1,006 & Tidak terjadi multikolinearitas \\
\hline
\end{tabular}

Sumber: Data primer yang diolah (2019).

Hasil uji Multikolinieritas pada Tabel 2 menjelaskan seluruh variabel independen memiliki VIF diantara 1 hingga 10 sehingga tidak terjadi multikolinieritas.

Tabel 3 Hasil Uji Park Glejser

\begin{tabular}{lc}
\hline Variabel & Significance \\
\hline Financial Attitude & 0.140 \\
Financial Knowledge & 0.482 \\
Financial Behavior & 0.391 \\
Financial Education & 0.180 \\
Financial Experience & 0.079
\end{tabular}

Sumber: Data primer yang diolah (2019). Hasil dari Tabel 3 dapat dijelaskan bahwa tidak terjadi heteroskedastisitas pada seluruh variabel karena memiliki nilai diatas 0.05 .

Tabel 4 Hasil Uji F

\begin{tabular}{lll}
\hline Model & Sig & Keterangan \\
\hline Regression & 0,000 & Signifikan \\
\hline
\end{tabular}

Sumber: Data primer yang diolah (2019). 
Pada Tabel 4 dapat dijelaskan bahwa hasil dari uji $\mathrm{F}$ tidak menggapai nilai 0.05 , sehingga dapat dinyatakan secara simultan terdapat hubungn antar variabel independen dengan variabel dependen.

Tabel 4.12 Hasil Uji Hipotesis

\begin{tabular}{lcccl}
\hline $\begin{array}{l}\text { Variabel } \\
\text { Independen }\end{array}$ & $\begin{array}{c}\text { Standardized } \\
\text { Coefficients (B) }\end{array}$ & Sig. & Hasil & Keterangan \\
\hline Financial Attitude & 0.130 & 0.009 & $\underline{\text { Signifikan Positif }}$ & Diterima \\
Financial Knowledge & 0.080 & 0.206 & $\underline{\text { Tidak Signifikan }}$ & Ditolak \\
Financial Behavior & -0.222 & 0.001 & $\underline{\text { Signifikan Negatif }}$ & Ditolak \\
Financial Education & 0.103 & 0.083 & $\underline{\text { Tidak Signifikan }}$ & Ditolak \\
Financial Experience & 0.318 & 0.000 & Signifikan Positif & Diterima \\
\hline
\end{tabular}

Sumber: Data primer yang diolah (2019).

H1 : Financial Attitude berpengaruh signifikan positif terhadap Financial Literacy

Variabel financial attitude mempunyai nilai signifikan sebesar 0.009 dan beta sebesar 0.130. Maka itu, H1 diterima dengan arti Financial Attitude berhubungan signifikan positif terhadap literasi keuangan pelajar atau mahasiswa di Kota Batam. Ternyata pelajar mengetahui pentingnya menabung, mencatat arus kas suatu bisnis, dan membeli sesuatu didasarkan skala prioritas sehingga literasi keuangan baik. Hasil tersebut sesuai dengan Sri Widiyati et al., (2018), Meli Ameliawati et al., (2018), Sang-Hee Sohn et al., (2012), Muhammad I. Albeerdy et al., (2015), Yoshihiko Kadoya et al., (2017), Kamini Rai et al., (2019), Tali Te'eni-Harari (2016), R. Venkataraman et al., (2018), A Firli (2017), dan Sazana Ab Rahman et al., (2018).

\section{H2 : Financial Knowledge} berpengaruh signifikan positif terhadap Financial Literacy

Variabel financial knowledge memiliki nilai signifikan sebesar 0.206 dan beta sebesar 0,080 dimana berada diatas 0.05. Maka itu, H2 ditolak dengan arti Financial Knowledge tidak memiliki hubungan terhadap literasi keuangan pelajar atau mahasiswa di Kota Batam. Financial Knowledge di Kota Batam tidak memiliki pengaruh baik pada pelajar, contohnya seperti tidak mengerti tingkat bunga yang menguntungkan, tidak mengerti saldo awal dan akhir, maupun tidak memahami nilai uang dengan baik. Sehingga pengetahuan keuangan tidak mendorong literasi keuangan seseorang. Hasil tersebut sesuai dengan Bart Frijns et al., (2013), Kamini Rai et al., (2019), dan Dahlia Ibrahim et al., (2009).

H3 : Financial Behavior berpengaruh signifikan positif terhadap Financial Literacy

Variabel financial behavior memiliki nilai signifikan sebesar 0.001. Maka itu, H3 ditolak dengan arti Financial Behavior signifikan negatif terhadap literasi keuangan pelajar atau mahasiswa di Kota Batam karena standardized coefficient berada pada beta -0.222 (posisi negatif). Semakin baik tingkah laku terhadap pelajar Kota Batam, semakin rendah literasi keuangan karena pelajar Kota Batam tidak pandai membandingkan mana yang lebih diprioritaskan dimana lebih mengutamakan keinginan daripada kebutuhan sehingga literasi keuangan merosot. Hasil tersebut sesuai dengan R. Venkataraman et al., (2018) dan George Okello Candiya et al., (2017).

H4 : Financial Education berpengaruh signifikan positif terhadap Financial Literacy

Variabel financial education memiliki nilai signifikan sebesar 0.083 dengan beta 0.103 dimana berada diatas 0.05. Maka itu, H4 ditolak dengan arti Financial Education tidak memiliki hubungan terhadap literasi keuangan pelajar atau mahasiswa di Kota Batam. Pelajar Kota Batam tidak paham cara menghitung laba rugi maupun balance sheet, pelajar juga berpikir bahwa semua jenis investasi menguntungkan. Hal tersebut membuktikan pendidikan keuangan pelajar tidak membantu literasi keuangan individu. Hasil tersebut sesuai dengan Partono Thomas et al., (2016). 
H5 : Financial

Experience berpengaruh signifikan positif terhadap Financial Literacy

Variabel financial experience memiliki nilai signifikan sebesar 0.000 pada beta 0,318. Maka itu, H5 diterima dengan arti Financial Experience berhubungan signifikan terhadap literasi keuangan pelajar atau mahasiswa di Kota Batam. Financial Experience pada pelajar Kota Batam dikategorikan baik karena pelajar mengerti pengelolaan keuangan yang baik untuk kedepannya berdasarkan pengalamannya. Selain itu, pelajar juga dapat memotivasi diri untuk mencapai tujuan dengan jangka panjang, serta menghabiskan uang dengan bijak. Hasil tersebut sesuai dengan penelitian Meli Ameliawati et al., (2018), Sang-Hee Sohn et al., (2012), Bart Frijns et al., (2013), Jacqueline Bartley (2011), Emma Floyd (2015), dan Mohammad Fazli et al., (2010).

Tabel 4.13 Hasil $\mathrm{R}^{2}$ Adjusted

\begin{tabular}{cc}
\hline $\mathrm{R}^{2}$ & Adjusted R Square \\
\hline 0.146 & 0.136
\end{tabular}

Sumber: Data primer yang diolah (2019).

Hasil penelitian uji hipotesis $R^{2}$ Adjusted menyimpulkan bahwa data-data yang terdapat pada variabel telah diuji serta memiliki model regresi sebesar 0.136 atau $13.6 \%$ variabel dependen adalah financial literacy yang dipengaruhi oleh lima variabel dependen yaitu financial attitude, financial education, financial knowledge, financial experience, dan financial behavior.

\section{Kesimpulan}

\section{KESIMPULAN,} KETERBATASAN, DAN REKOMENDASI

Berdasarkan hasil penelitian pada pelajar Kota Batam, dapat disimpulkan bahwa financial attitude dan financial experience berpengaruh signifikan positif terhadap financial literacy. Tetapi financial behavior berpengaruh signifikan negatif terhadap financial literacy. Sedangkan financial knowledge dan financial education tidak memiliki hubungan signifikan terhadap financial literacy.

\section{Keterbatasan}

Keterbatasan dari penelitian ini adalah keterbatasan peneliti untuk menggali informasi lebih dalam tentang literasi keuangan seseorang, dimana penelitian hanya melalui penyebaran kuesioner yang terkadang jawaban responden tidak menggambarkan keadaan secara nyata. Selain itu, beberapa responden tidak mengisi kuesioner dengan lengkap sehingga data tersebut tidak dapat diolah serta ukuran sampel yang terbatas. Faktor yang diteliti hanya beberapa faktor, tetapi terdapat banyak faktor-faktor lain yang berhubungan dengan literasi keuangan yang tidak dicantumkan.

\section{Rekomendasi}

Seharusnya peneliti mendata murid-murid yang sedang berada pada jenjang SMA ataupun SMP sehingga sampel yang didapatkan akan lebih maksimal. Dari hasil penelitian, dapat dinyatakan bahwa literasi keuangan masyarakat tidak sepenuhnya baik, sebaiknya diberikan program pelatihan ataupun seminar tentang literasi keuangan, agar masyarakat memanfaatkan uang dengan baik.

\section{DAFTAR PUSTAKA}

Adiana, A. M. (2015). Konsumtif itu Karena Apa?

Agarwalla, S. K., Barua, S. K., Jacob, J., \& Varma, J. R. (2015). Financial Literacy among Working Young in Urban India. World Development, 67(2013), 101-109. https://doi.org/10.1016/j.worlddev.2 014.10 .004

Albeerdy, M. I., \& Gharleghi, B. (2015). Determinants of the Financial Literacy among College Students in Malaysia. International Journal of Business Administration, 6(3), 1524. https://doi.org/10.5430/ijba.v6n3p15

Alex, K., \& Amos, A. (2014). The Role of Financial Literacy in Promoting 
Children \&amp; Youth Savings Accounts: A Case of Commercial Banks in Kenya. Research Journal of Finance and Accounting, 5(11), 2222-2847. Retrieved from http://citeseerx.ist.psu.edu/viewdoc/d ownload?doi=10.1.1.894.21\&rep=re p1\&type $=$ pdf

Ameliawati, M., \& Setiyani, R. (2018). The Influence of Financial Attitude, Financial Socialization, and Financial Experience to Financial Management Behavior with Financial Literacy as the Mediation Variable. KnE Social Sciences, $3(10), \quad 811$. https://doi.org/10.18502/kss.v3i10.3 174

Bartley, J. (2011). Financial Literacy Among the Young. SSRN Electronic Journal, 7(1).

https://doi.org/10.2139/ssrn.1476982

Beckmann, E. (2013). Numeracy

Advancing Education in Quantitative Literacy Financial Literacy and Household Savings in Romania Financial Literacy and Household Savings in Romania. 6(9). https://doi.org/10.5038/19364660.6.2.9

Candiya Bongomin, G. O., Munene, J. C., Ntayi, J. M., \& Malinga, C. A. (2017). Financial literacy in emerging economies. Managerial Finance, 43(12), 1310-1331. https://doi.org/10.1108/mf-04-20170117

Choudhary, K., Professor, A., \& Kamboj, S. (2017). Women and Financial Literacy: An Empirical Study from Haryana. International Research Journal of Commerce and Law (Impact Factor-4.616) A Monthly Double-Blind Peer Reviewed Refereed Open Access International $e$-Journal-Included in the International Serial Directories International Research Journal of Commerce and Law, 04(8), 23492705. Retrieved from http://www.ijmr.net.inhttp//www.ijm r.net.in

Chung, Y., \& Park, Y. (2016). The

Effects Of Financial Education And

Networks On Business Students

Financial Literacy. American

Journal of Business Education

(AJBE), 7(3), 229.

https://doi.org/10.19030/ajbe.v7i3.86

32

de Bassa Scheresberg, C. (2013).

Financial Literacy and Financial

Behavior among Young Adults:

Evidence and Implications.

Numeracy, 6(2).

https://doi.org/10.5038/1936-

4660.6.2.5

Dewanty, N., \& Isbanah, Y. (2018).

Determinant of The Financial

Literacy: Case Study on Career

Woman in Indonesia. Etikonomi, 17(2), 285-296.

https://doi.org/10.15408/etk.v17i2.66 81

Fazli Sabri, M., MacDonald, M., K.Hira, T., \& Masud, J. (2010). childhood consumer experiene and the financial literacy of College students in malaysia.

Fernandes, D., Lynch, J. G., \& Netemeyer, R. G. (2014). Financial literacy, financial education, and downstream financial behaviors. Management Science, 60(8), 18611883.

https://doi.org/10.1287/mnsc.2013.1 849

Floyd, E. (2015). Measuring Financial Literacy: A comparative study across two collegiate groups.

Frijns, B., Gilbert, A., \& Tourani-Rad, A. (2014). Learning by doing: The role of financial experience in financial literacy. Journal of Public Policy, 34(1), 123-154. https://doi.org/10.1017/S0143814X1 3000275

Graf, R. (2012). Financial Literacy and Financial Behavior in Switzerland. DIW Economic Bulletin, 30(31), 1133. 
Ibrahim, D., Harun, R., \& Mohamed Isa, Z. (2009). A Study on Financial Literacy of Malaysian Degree Students The efficiency of waqf performance View project A Study on Financial Literacy of Malaysian Degree Students UNE ÉTUDE SUR LES CONNAISSANCES FINANCIÈRES DES ÉTUDIANTS MALAISIENS. Canadian Academy of Oriental and Occidental Culture, 5(4), 51-59.

https://doi.org/10.3968/j.ccc.192367 0020090504.006

Isomidinova, G., \& Singh, J. S. K. (2017). Determinants of financial literacy : a quantitative study among young students in Tashkent, Uzbekistan. Electronic Journal of Business \& Management, 2(1), 61-75.

Jatmiko, L. D. (2018). Rendahnya Literasi Masyarakat Hambat Penetrasi Lembaga Keuangan Syariah. Retrieved from bisnis.com website: https://finansial.bisnis.com/read/201 80919/232/839782/rendahnyaliterasi-masyarakat-hambatpenetrasi-lembaga-keuangan-syariah

Kadoya, Y., \& Khan, M. (2017).

Explaining Financial Literacy in Japan: New Evidence Using Financial Knowledge, Behavior, and Attitude. Ssrn, (February). https://doi.org/10.2139/ssrn.3067799

Kane, S. N., Mishra, A., \& Dutta, A. K. (2016). Preface: International Conference on Recent Trends in Physics (ICRTP 2016). Journal of Physics: Conference Series, 755(1). https://doi.org/10.1088/17426596/755/1/011001

Kebede, M., \& Kuar, J. (2015). Financial Literacy and Management of Personal Finance: A Review of Recent Literatures. Research Journal of Finance and AccountingOnline), 6(13), 2222-2847.

Kholilah, N. Al, \& Iramani, R. (2013). Studi Financial Management Behavior Pada Masyarakat Surabaya.
Journal of Business and Banking, 3, 69-80.

https://doi.org/http://dx.doi.org/10.14 414/jbb.v3i1.255

KoranSINDO. (2019). Literasi Keuangan Harus Diajarkan Sejak Dini.

Lusardi, A. (2012). Numeracy, Financial Literacy, and Financial. Journal International of Numeracy, 5(1), 112.

https://doi.org/http://dx.doi.org/10.50 38/1936-4660.5.1.2

Mudzingiri, C., Muteba Mwamba, J. W., \& Keyser, J. N. (2018). Financial behavior, confidence, risk preferences and financial literacy of university students. Cogent Economics and Finance, 6(1), 1-25. https://doi.org/10.1080/23322039.20 18.1512366

Murugiah, L. (2016). The level of understanding and strategies to enhance financial literacy among Malaysian. International Journal of Economics and Financial Issues, 6(3), 130-139.

Mwange, A., Lis, B. A., Epm, M. A., Ib, M. B. A., \& Candidate, D. B. A. (2017). IJRDO-Journal of Business Management Exploring Levels of Financial Literacy among University of Zambia Final Year Students. (3), 81-92.

Nicolini, G., \& Nicolini, G. (2019). Financial literacy and financial behavior. Financial Literacy in Europe, (October), 85-140. https://doi.org/10.4324/97804294319 68-3

Nidar, S. R., \& Bestari, S. (2012). nidar dan bestari_Sulaeman.2(4), 162171.

Philippas, N. D., \& Tzora, V. A. (2017). A Financial Literacy Survey among University Students in Greece. Global, Economics, Finance and Social Sciences, (April), 1-21.

Potrich, A. C. G., Vieira, K. M., \& Kirch, G. (2015). Determinants of financial literacy: Analysis of the influence of 
socioeconomic and demographic variables. Revista Contabilidade e Financas, 26(69), 362-377. https://doi.org/10.1590/1808057x201501040

Rahman, S. A., Tajudin, A., Fadzli, A., \& Tajuddin, A. (2018). Determinant Factors of Islamic Financial Literacy In Malaysia. American Journal of Humanities and Social Sciences Research, (10), 125-132. Retrieved from www.ajhssr.com

Rai, K., Dua, S., \& Yadav, M. (2019). Association of Financial Attitude, Financial Behaviour and Financial Knowledge Towards Financial Literacy: A Structural Equation Modeling Approach. FIIB Business Review, 8(1), 51-60. https://doi.org/10.1177/23197145198 26651

Segara, T. (2016). Survei Nasional Literasi dan Inklusi Keuangan 2016. Setyawati, I., \& Suroso, S. (2017). Does the Sharia Personal Financial Management Require? Study of Sharia Financial Literacy Among Lecturers. International Journal of Economics and Financial Issues, 7(4), 411-417.

Sohn, S. H., Joo, S. H., Grable, J. E., Lee, S., \& Kim, M. (2012). Adolescents' financial literacy: The role of financial socialization agents, financial experiences, and money attitudes in shaping financial literacy among South Korean youth. Journal of Adolescence, 35(4), 969-980. https://doi.org/10.1016/j.adolescence .2012 .02 .002

Suparti, S. (2016). Mitigating

Consumptive Behavior: The Analysis of Learning Experiences of Housewives. International Education Studies, 9(3), 114. https://doi.org/10.5539/ies.v9n3p114 Te'eni-Harari, T. (2016). Financial literacy among children: the role of involvement in saving money. Young Consumers, 17(2), 197-208.
https://doi.org/10.1108/YC-01-201600579

Thomas, P., Mulyono, B., Setiaji, K., \& Thomas, P. (2016). The Roles of Financial Knowl-edge, Motivation and Self Efficacy on the Influence of Financial Education toward Financial Literacy. Dinamika Pendidikan, 11(2), 149-157. https://doi.org/10.15294/dp.v11i2.89 41

Venkataraman, R., \& Venkatesan, T. (2018). Analysis of Factors Determining Financial Literacy using Structural Equation Modelling\#. SDMIMD Journal of Management, 9(1), 1-11. https://doi.org/10.18311/sdmimd/201 8/19998

Widiyati, S., Wijayanto, E., Akuntansi, J., Negeri Semarang, P., ProfSoedarto, J. S., \& Semarang, T. (2018).

Financial Literacy Model at Micro Small Medium Entreprise (MSMEs) 1. 34(2), 255-264. https://doi.org/10.29313/mimbar.v34 i2.2914.255-264

Yıldırım, M., Bayram, F., Oğuz, A., \& Günay, G. (2017). Financial Literacy Level of Individuals and Its Relationships to Demographic Variables. Mediterranean Journal of Social Sciences, 8(3), 19-26. https://doi.org/10.5901/mjss.2017.v8 n3p19

Yong, C. C., Yew, S. Y., \& Wee, C. K. (2018). Financial knowledge, attitude and behaviour of young working adults in Malaysia. Institutions and Economies, 10(4), 21-48. 